\title{
The Role of Mutations on Gene NAGA, in Schindler Syndrome
}

Shahin Asadi*, Amir Houssein Kiani, Mohaddeseh Mohsenifar

Division of Medical Genetics and Molecular Pathology Research, Harvard University, Boston Children's Hospital.

*Corresponding Author: Shahin Asadi, Medical Genetics-Harvard University. Director of the Division of Medical Genetics and Molecular Optogenetic Research \& Massachusetts Institute of Technology (MIT), Division of Medical Genetics and Molecular Pathology Research, Harvard University, Boston Children's Hospital.

Received date: October 23, 2020; Accepted date: December 29, 2020; Published date: January 05, 2020

Citation: S Asadi, Amir H Kiani, M Mohsenifar. (2021) The Role of Mutations on Gene NAGA, in Schindler Syndrome. Biomedical Research and Clinical Reviews. 3(1); DOI:10.31579/2692-9406/029

Copyright: (C) 2021 Shahin Asadi, This is an open-access article distributed under the terms of the Creative Commons Attribution License, which permits unrestricted use, distribution, and reproduction in any medium, provided the original author and source are credited.

\begin{abstract}
Schindler syndrome is an inherited genetic disorder that mainly causes neurological problems. Schindler's syndrome is caused by a mutation in the NAGA gene, which is located in the long arm of chromosome 22 as $22 \mathrm{q} 13.2$.
\end{abstract}

Keywords: schindler syndrome; genetic disorder; naga gene; kanzaki disease

\section{Generalities of Schindler Syndrome}

Schindler syndrome is an inherited genetic disorder that mainly causes neurological problems. Three types of Schindler syndrome have been identified, including type I (neonatal form and most severe), type II (adult and milder form), and type III, which is the median between type I and type II [1].

\section{Clinical Signs and Symptoms of Schindler's Syndrome}

As mentioned, three types of Schindler syndrome have been identified so far. Schindler syndrome type 1, also known as neonatal form, is the most severe form of this syndrome. Babies with Schindler's syndrome type 1 appear healthy at birth, but at 8 to 15 months of age, they begin to lose learned skills (developmental regression) and delay the development of new daily life skills. Are accompanied. As the disease progresses, people with type 1 syndrome also experience blindness and seizures, and eventually lose awareness of their surroundings and do not respond appropriately. People with Schindler's syndrome type 1 usually die in childhood [1, 2].

Schindler's syndrome type 2 is also known as Kanzaki disease, which is milder than type 1 syndrome and is most commonly seen in adulthood. Affected individuals may develop mild cognitive impairment and hearing loss due to inner ear abnormalities (sensory hearing loss). They may experience feelings of weakness and inability due to neurological problems that connect the brain and spinal cord to muscles and sensory cells (peripheral nervous system). Large clusters of blood vessels that form small, dark red spots on the skin (angiocratoma) are characteristic of this form of Schindler's syndrome [1, 3].

Schindler's syndrome is type 3 , intermediate between type 1 (severe) and type 2 (mild). Affected individuals may show signs and symptoms at birth, including growth retardation, seizures, large and weak heart muscle (cardiomyopathy), and large liver (hepatomegaly). In other cases, people with this type of disorder in early childhood show behavioral problems with some of the characteristics of autism spectrum disorders. Autism spectrum disorders are characterized by impaired communication and social skills $[1,4]$.

\section{Etiology of Schindler Syndrome}

Schindler's syndrome is caused by a mutation in the NAGA gene, which is located in the long arm of chromosome 22 as $22 q 13.2$. This gene provides the instructions for the synthesis of the enzyme alpha $\mathrm{N}$-acetyl galactosaminidase. This enzyme works on lysosomes, which are the parts of cells that digest and recycle materials. Within lysosomes, this enzyme helps break down complexes called glycoproteins and glycolipids, which are made up of sugar molecules attached to specific proteins and fats. In particular, alpha $\mathrm{N}$-acetyl galactosaminidase helps remove a molecule called alpha $\mathrm{N}$-acetyl galactosamine from the sugars in these complexes $[1,5]$. 


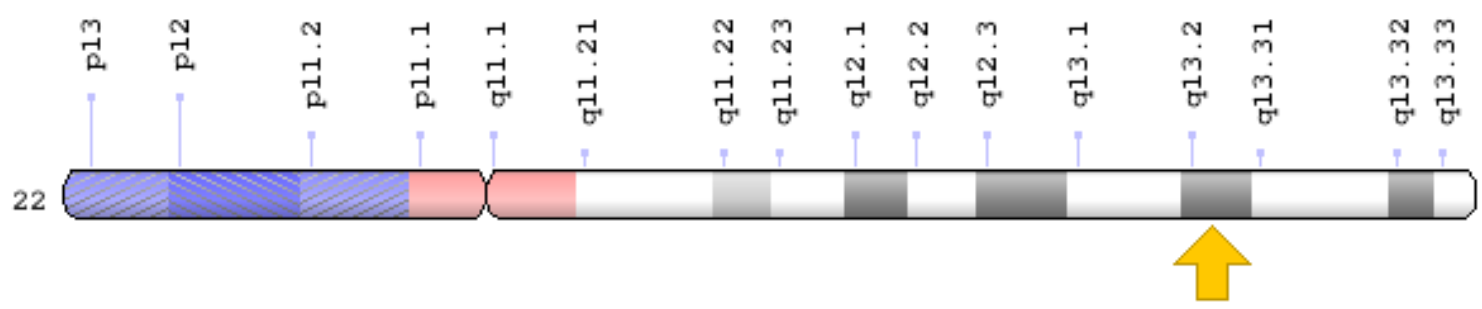

Figure 1: Schematic view of chromosome 22 where the NAGA gene is located in the long arm of this chromosome as $22 \mathrm{q} 13.2 .1$

Mutations in the NAGA gene interfere with the ability of the enzyme alpha-N-acetyl galactosaminidase and disrupt its role in the breakdown of glycoproteins and glycolipids. As a result, these substances accumulate in the lysosomes, leading the cells to malfunction, and eventually, the cells die. Cellular damage to the nervous system and other tissues and organs of the body leads to the signs and symptoms of Schindler syndrome [1, 6].

Schindler's syndrome follows an autosomal recessive inherited pattern. Therefore, two copies of the mutated NAGA gene (one from the father and the other from the mother) are required to cause this syndrome, and the chance of having a child with this autosomal recessive syndrome is $25 \%$ for each possible pregnancy $[1,7]$.

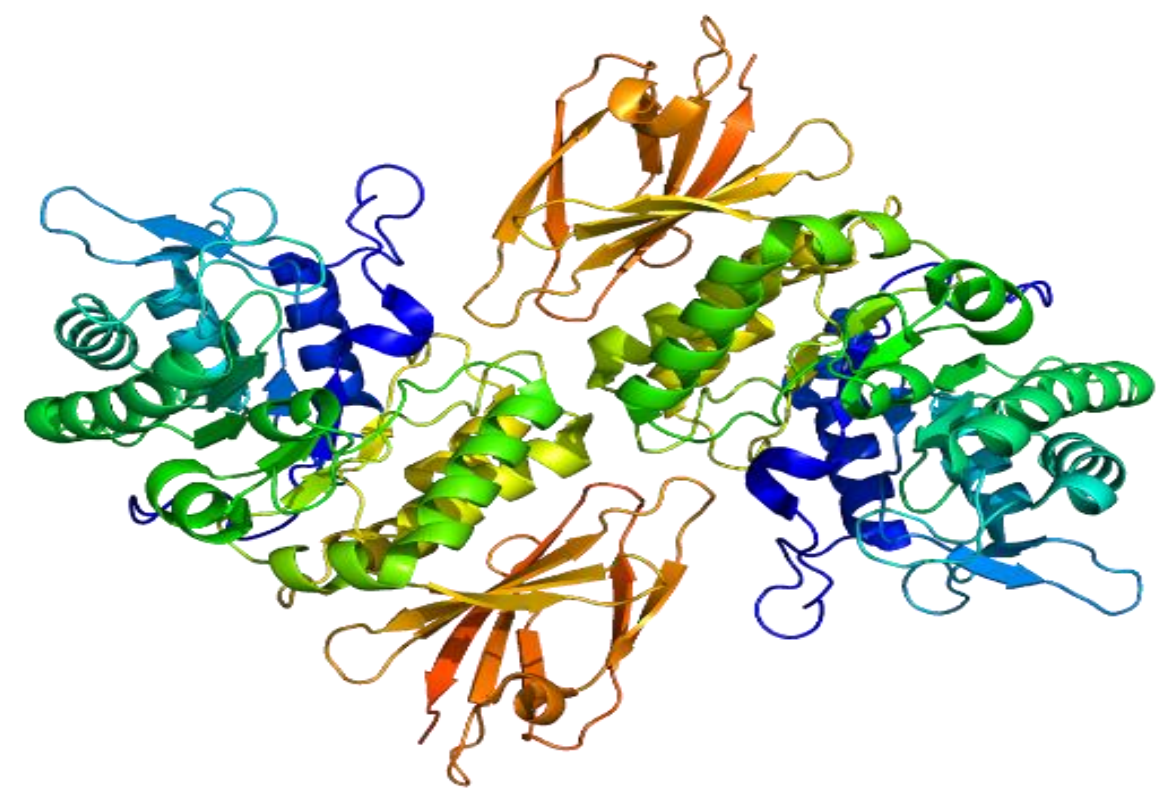

Figure 2: Schematic of the closed structure of the alpha-N-acetyl galactosaminidase enzyme

\section{Frequency of Schindler Syndrome}

Schindler's syndrome is a very rare genetic disorder that has only been reported in the medical literature $[1,8]$.

\section{Diagnosis of Schindler Syndrome}

Schindler's syndrome is diagnosed based on the clinical findings of some patients and some pathological and neurological tests. The most accurate way to diagnose this syndrome is to test molecular genetics for the NAGA gene to check for possible mutations $[1,9]$. 
<smiles>CC(=O)NC(O)C(O)C(O)CO</smiles>

$\mathrm{C}_{8} \mathrm{H}_{15} \mathrm{NO}_{6}$ 221.089937

DeltaMass: 203.0794<smiles>CC(=O)N[C@H]1C(O)O[C@H](CO)[C@@H](O)C1O</smiles><smiles>C=C(C)C(C)C(C)C1C(CC)CC(C(C)CC)C(Cl)C1CC</smiles>

\section{N-Acetylgalactosamine or GalNAc}

Figure 3: Schematic of the cyclic structure of the GalNAc enzyme

\section{Treatment options for Schindler's Syndrome}

The treatment and management strategy for Schindler's syndrome is symptomatic and supportive. Treatment may be performed with the efforts and coordination of a team of specialists including a pediatrician, a pediatric neurologist, a physical therapist, an audiologist, a cardiologist, a liver specialist, and other health care professionals. There is no effective treatment for this syndrome and all clinical measures are taken to alleviate the suffering of the patients. Genetic counseling is also essential for all parents who want a healthy baby $[1,10]$.

\section{History of Schindler Syndrome}

Schindler syndrome was first reported in 1988 by Dr. Detlev Schindler and then more fully described by Japanese physician and biochemist Dr. Hiro Kanzaki in 2006 [1, 11].

\section{Autosomal Recessive Inheritance Pattern}

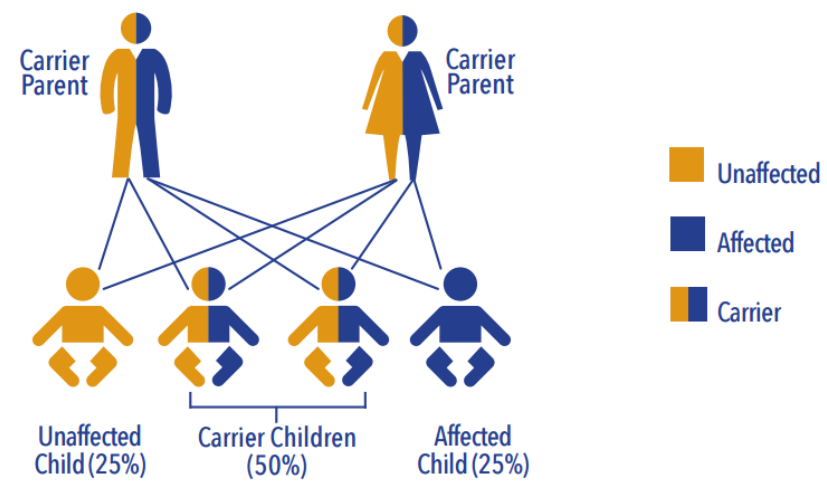

Figure 4: Schematic of the autosomal recessive inherited pattern followed by Schindler syndrome

\section{Discussion and Conclusion}

Babies with Schindler's syndrome type 1 appear healthy at birth, but at 8 to 15 months of age, they begin to lose learned skills (developmental regression) and delay the development of new daily life skills. Are accompanied. Schindler's syndrome is caused by a mutation in the NAGA gene, which is located in the long arm of chromosome 22 as $22 \mathrm{q} 13.2$. This gene provides the instructions for the synthesis of the enzyme alpha $\mathrm{N}$ acetyl galactosaminidase. Treatment may be performed with the efforts and coordination of a team of specialists including a pediatrician, a pediatric neurologist, a physical therapist, an audiologist, a cardiologist, a liver specialist, and other health care professionals $[1,11]$.

\section{References}

1. Asadi S. (2020) Pathology in Medical Genetics Book, Vol 16, Amidi Publications, Iran. 1435-1446.

2. Chabás A, Duque J, Gort L. (2007) A new infantile case of alpha-N-acetylgalactosaminidase deficiency. Cardiomyopathy as a presenting symptom. J Inherit Metab Dis 30(1):108.
3. Clark NE, Garman SC. (2009) The 1.9 a structure of human alpha-N-acetylgalactosaminidase: The molecular basis of Schindler and Kanzaki diseases. J Mol Biol. 393(2):435-47.

4. Desnick RJ, Wang AM. (1990) Schindler disease: an inherited neuroaxonal dystrophy due to alpha- $\mathrm{N}$-acetylgalactosaminidase deficiency. J Inherit Metab Dis. 13(4):549-559.

5. Kanda A, Tsuyama S, Murata F, Kodama K, Hirabayashi Y, Kanzaki T. (2002) Immunoelectron microscopic analysis of lysosomal deposits in alpha- $\mathrm{N}$-acetylgalactosaminidase deficiency with angiokeratoma corporis diffusum. J Dermatol Sci. 29(1):42-48.

6. Kanekura T, Sakuraba H, Matsuzawa F, Aikawa S, Doi H, Hirabayashi Y, Yoshii N, Fukushige T, Kanzaki T. (2005) Three dimensional structural studies of alpha-Nacetylgalactosaminidase (alpha-NAGA) in alpha-NAGA deficiency (Kanzaki disease): different gene mutations cause peculiar structural changes in alpha-NAGAs resulting in different substrate specificities and clinical phenotypes. J Dermatol Sci. 37(1):15-20. 
7. Kanzaki T, Yokota M, Irie F, Hirabayashi Y, Wang AM, Desnick RJ. (1993) Angiokeratoma corporis diffusum with glycopeptiduria due to deficient lysosomal alpha-Nacetylgalactosaminidase activity. Clinical, morphologic, and biochemical studies. Arch Dermatol. 129(4):460-465.

8. Kodama K, Kobayashi H, Abe R, Ohkawara A, Yoshii N, Yotsumoto S, Fukushige T, Nagatsuka Y, Hirabayashi Y, Kanzaki T. (2001) A new case of alpha-Nacetylgalactosaminidase deficiency with angiokeratoma corporis diffusum, with Ménière's syndrome and without mental retardation. Br J Dermatol. 144(2):363-368.

9. Michalski JC, Klein A. (1999) Glycoprotein lysosomal storage disorders: alpha- and beta-mannosidosis, fucosidosis and alpha$\mathrm{N}$-acetylgalactosaminidase deficiency. Biochim Biophys Acta. 1455(2-3):69-84.

10. Sakuraba H, Matsuzawa F, Aikawa S, Doi H, Kotani M, Nakada H, Fukushige T, Kanzaki T. (2004) Structural and immunocytochemical studies on alpha-Nacetylgalactosaminidase deficiency (Schindler/Kanzaki disease). J Hum Genet.49 (1):1-8.

11. Umehara F, Matsumuro K, Kurono Y, Arimura K, Osame M, Kanzaki T. (2004) Neurologic manifestations of Kanzaki disease. Neurology. 62(9):1604-1606. 